\title{
LMO T-cell translocation oncogenes typify genes activated by chromosomal translocations that alter transcription and developmental processes
}

\author{
Terence H. Rabbitts ${ }^{1}$ \\ Medical Research Council (MRC) Laboratory of Molecular Biology, Division of Protein and Nucleic Acid Chemistry, \\ Cambridge CB2 2QH, UK
}

The cytogenetic analysis of tumors, particularly those of hematopoietic origin, has revealed that reciprocal chromosomal translocations are recurring features of these tumors. Further from the initial recognition of the translocation t(9;22) (Nowell and Hungerford 1960; Rowley 1973), it has become clear that particular chromosomal translocations are found consistently in specific tumor subtypes. A princi ple example of this is the transl ocation $t(8 ; 14)(q 24 ; q 32.1)$ invariably found in the human B cell tumor Burkitt's Iymphoma (Manolov and M anolov 1972; Zech et al. 1976). The link with the immunoglobulin $\mathrm{H}$-chain locus on chromosome 14, band q32.1 (Croce et al. 1979; Hobart et al. 1981) and subsequently with the K light-chain locus on chromosome 2, band p12 (M alcolm et al. 1982), suggested that the immunoglobulin genes might be associated with the translocation breakpoints. The cloning of the CMYC proto-oncogene associated with the IgH locus from Burkitt's Iymphoma translocation breakpoint $\mathrm{t}(8 ; 14)(\mathrm{q} 24 ; \mathrm{q32})$ confirmed this. Through the subsequent cloning of the chromosomal breakpoints in other tumors and identification of oncogenes at many different breakpoints, followed by transgenic (Adams and Cory 1991) and homologous recombination knockin analysis (Corral et al. 1996), it has become clear that abnormal tumor-associated chromosomal translocations are important in the etiology of tumors (for review, see Rabbitts 1994). The scientific challenge of the last decade has been to define the contribution of the genes activated by translocations to the course of tumor development and to ascertain whether any general principles can be determined about these 'translocation' genes.

There are two main outcomes of chromosomal translocations in human tumors (for review, see Rabbitts 1994). The first is confined to the lymphoid tumors in which the process of antigen receptor gene rearrange-

IFAX (01223) 412178. ment (immunoglobulin or T-cell receptor) occurs and occasionally mediates chromosomal translocation. This type of translocation causes oncogene activation resulting from the new chromosomal environment of the rearranged gene. In general, this means inappropriate gene expression. The second, and probably the most common outcome of chromosomal translocations, is gene fusion in which exons from a gene on each of the invol ved chromosomes are linked after the chromosomal translocation, resulting in a fusion mRNA and protein. This type of event is found in many cases of hematopoietic tumors and in the sarcomas.

These general observations posed many questions about chromosomal translocations and how they might influence tumor growth and progression. The diversity of these aberrant chromosomes questioned whether any general principles might emerge. A particular enigma was the finding of diverse genes at chromosomal breakpoints. T-cell acuteleukemia (T-ALL) is one notable case in point. The disease is clinically rather constant, yet individual cases contain one of more than a dozen possible chromosomal transl ocations. The analysis of these has led to the discovery of many different, novel genes that can contribute to T-cell tumorigenesis (Rabbitts 1994).

The genes at breakpoints of many major transl ocations have now been cloned, and it has been shown that the protein products of these genes frequently have prominent features of transcription regulators, for example, the DNA-binding homeodomain of HOX11 in T-ALL (Dube et al. 1991; Hatano et al. 1991; Kennedy et al. 1991; Lu et al. 1991). Thus, a common theme about the genes activated or fused by chromosomal transl ocations is that they encode transcription regulators in their normal sites of expression (Cleary 1991; Rabbitts 1991; Look 1997). Furthermore, it appears to be this property that can be instrumental in their involvement in tumor etiology following the chromosomal translocation. In 
addition, the biological role of many chromosomal translocation-activated genes is normally in developmental processes leading to the idea that subversion of development may be their crucial biological role in tumorigenesis, perhaps explaining why so few of the chromosomal translocation-activated genes were identified previously as oncogenes by other experimental approaches.

This article summarizes a series of observations on the LMO T-cell oncogenes that embody many of the salient features of the chromosomal translocation-activated genes. The results also show that the study of these naturally occurring mutations have hel ped in the understanding of mechanisms in hematopoiesis and act as a paradigm, underscoring the conclusion that protein-protein interactions are a key determinant in tumorigenesis and in hematopoiesis.

\section{The LMO family of T-cell oncogenes}

The LMO (는-only) family of genes (Table 1) was uncovered by the association of LMO1 (previously called RBTN 1 or TTG1) with the chromosomal translocation $t(11 ; 14)(p 15 ; q 11)$. The transcription unit was first observed in a T-cell line (Boehm et al. 1988), and the mRN A sequence was obtained from its CDN A sequence (McGuire et al. 1989; Boehm et al. 1990b) and shown to encode a protein essentially consisting of two zinc-binding LIM domains (Boehm et al. 1990a). Using an LMO1 probe, the two related genes LMO 2 and LMO 3 were isolated (previously called RBTN2 or TTG2 and RBTN3, respectively) (Boehm et al. 1991; Foroni et al. 1992), of which LMO2 was found located at the junction of the chromosomal translocation $\mathrm{t}(11 ; 14)(\mathrm{p} 13 ; \mathrm{q} 11)$ in $\mathrm{T}-\mathrm{ALL}$ (Boehm et al. 1991; Royer-Pokora et al. 1991). As proposed for other translocations (Finger et al. 1986), the LMO-associated chromosomal translocations appear to have occurred by an error of the RAG-mediated V(D)] recombinase process, as sequence analysis of the breakpoints on chromosome 11p13 detected recombinase signal-like sequences at the junctions and because the joins on chromosome 14, in the TCR $\delta$ locus, or on chromosome 7, in the TCR $\beta$ locus, occur precisely at the end of TCR D or J segments (Sanchez-Garcia et al. 1991). This association with mistakes by $\mathrm{V}(\mathrm{D}) \mathrm{J}$ recombinase seems

Table 1. The LMO family of genes and T-cell oncogenes

\begin{tabular}{|c|c|c|c|}
\hline \multirow[b]{2}{*}{ Gene } & \multicolumn{2}{|c|}{ Chromosome } & \multirow[b]{2}{*}{ Human translocation } \\
\hline & man & mouse & \\
\hline LMO1 & $11 p 15$ & 7 & $\mathrm{t}(11 ; 14)(p 15 ; q 11)$ \\
\hline LMO2 & $11 \mathrm{p} 13$ & 2 & t(11;14)(p13;q11) \\
\hline LMO3 & $12 \mathrm{p} 12-13$ & 6 & N.D. \\
\hline
\end{tabular}

The LM O gene family (previously called RBTN and TTG genes) has three known members. LMO1 (previously RBTN1/TTG1) was identified first and then LMO2 (previously RBTN2/TTG2) and LMO3 (previously RBTN3). LMO 1 and LMO2 are both Iocated on the short arm of chromosome 11 and are both involved in independent chromosomal translocations in human T-ALL. As yet, LMO 3 has not been found in association with any chromosomal translocations. (N.D.) N ot determined.

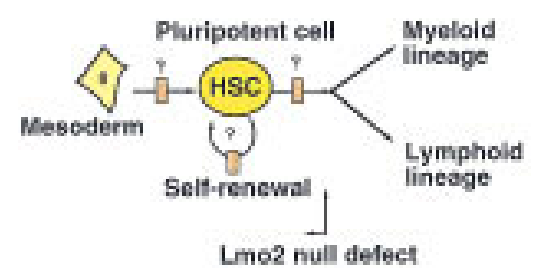

Figure 1. Lmo2 is necessary for adult hematopoiesis in mice. The tissue contribution of embryonic stem cells with homozygous null mutation of $\mathrm{Lmo} 2$ showed that hematopoiesis in adult mice is dependent on this gene (Yamada et al. 1998). Thus, the gene product is required for all stages of adult hematopoiesis, functioning at least prior to the bifurcation of myel oid and lymphoid lineages. The function may be restricted to the bone marrow stem cells (either at the self-renewal stage or at the proliferative stages that produce committed progenitors) or in the ventral mesoderm bone marrow precursor cells.

pertinent to the cell type involved in initiation of T-cell tumors (see below).

The unique feature of the LMO-derived protein se quences is that they are small proteins comprising two tandem LIM domains. These zinc-binding finger-like structures have structural similarities to the DN A-binding GATA fingers (Perez-Alvarado et al. 1994), but as yet no case of a direct, specific LIM-DNA interaction has been reported; rather the function of this domain appears to be restricted to protein-protein interaction (see below).

\section{Lmo2 is a regulator of hematopoiesis in normal mouse development}

To gain insights into the function of the LMO genes in tumorigenesis, an integrated approach has been adopted to attempt to understand normal function at the biological and molecular levels of LMO proteins and to utilize this information to explore the function in tumors. As a first step, gene targeting was used to introduce null mutations in the mouse Lmo2 gene, which showed that Lmo2 is necessary for yolk sac erythropoiesis in mouse embryogenesis (Warren et al . 1994). Furthermore, the use of ES cells with null mutations of both al leles of $\mathrm{Lmo} 2$ in chimeric mice has shown that adult hematopoiesis, including lymphopoiesis and myelopoiesis, fails completely in the absence of Lmo2 (Yamada et al. 1998). These data show that Lmo2 must function during the early stages of hematopoiesis at the level of the pluripotent stem cell, of the immediate multipotential progeny or even perhaps before this when ventral mesoderm gives rise to these precursors (Fig. 1). A significant similarity occurs with results described for another $\mathrm{T}$-cell oncogene Tal1/Scl (herein called Tal1) (Porcher et al. 1996; Robb et al. 1996). This gene was discovered be cause it is activated in a subset of human T-cell acute leukemias by chromosomal translocations or by promoter deletions (Begley et al. 1989a,b; Bernard et al. 1989; Finger et al. 1989; Chen et al. 1990a,b). The gene encodes a transcription factor, as the protein product has a basic-helix-loop-helix (bHLH) region (Begley et al. 1989a,b; Bernard et al. 1989; Finger et al. 1989; Chen et 
al. 1990a,b) and a transcriptional transactivation domain (Sanchez-Garcia and Rabbitts 1994; Wadman et al. 1994b). Tal 1 can heterodimerize with the bHLH protein E47 to form a DN A-binding complex, whereas Tal 1 homodimers do not bind to DNA (Hsu et al. 1991, 1994). The similarity in tumor tropism and effect of null mutations of Lmo2 and Tal 1 thus underlines the relationship of transcription and devel opment to oncogenesis resulting from chromosomal translocations.

\section{LMO2 functions by protein interaction: the role of the LIM domain}

The concept that translocation oncogenes can interfere with developmental processes because they normally perform this function may explain their role in tumor etiology. The involvement in development of hematopoietic lineages is cl ear for the Lmo2 transl ocation gene, leading to tests of mol ecular function in both normal and tumor cells. A particularly relevant observation was that the T-cell oncogenes Lmo 2 and Tal 1 were coexpressed in erythrocytes (Warren et al. 1994), suggesting a possible synergy between the function of the two proteins. This turned out to be even more germane, as it was shown that the Lmo2 and Tal 1 proteins could interact directly with each other (Valge-A rcher et al. 1994; Wadman et al. 1994a) mediated through the LIM domains. These observations and those made with isolated LIM fragments (Schmeichel and Beckerle 1994) established a role for the LIM domain in protein-protein interaction. The LIM domain does not seem to bind DNA directly despite the similarity to the GATA DNA-binding zinc finger.

The ability of the LIM domain to bind various proteins was al so shown in the ability of Lmo2 to bind to Gata-1 (Osada et al . 1995; Wadman et al . 1997) and to bind to the Ldb1/N li1 protein (Agulnick et al. 1996; Jurata et al. 1996; Bach et al. 1997; Wadman et al. 1997). LMO1 has also been shown to interact in vivo with LDB1 in T-ALL cell and neuroblastoma cell lines (Valge-Archer et al. 1998). This array of interactions led to the observation that $\mathrm{Lmo} 2$ can be found in an oligomeric complex in erythroid cells that involves Tal 1, E47, Ldb1, and Gata-1 (Wadman et al. 1997). This complex is able to bind DN A through the GATA and bHLH components, thereby recognizing a unique bipartite DNA sequence comprising an $E$ box separated by about one helix turn from a GATA site, with Lmo2 and Ldb1 proteins seeming to bridge the bi partite DNA-binding complex (Fig. 2A). These findings suggest that Lmo2 can be part of a transcription complex in hematopoiesis, and that this complex binds to and controls the expression of target genes during development. Furthermore, it is possible that different Lmo2containing compl exes may exist in different hematopoietic cell types, which may differ in the types of protein factors involved (Wadman et al. 1997). The involvement of Lmo2, Tal1, and GATA proteins in common DNAbinding complexes throughout hematopoiesis suggests that they regulate downstream target genes, perhaps explaining why the null mutation of each of these genes leads to lack of primitive erythropoiesis (Pevny et al.
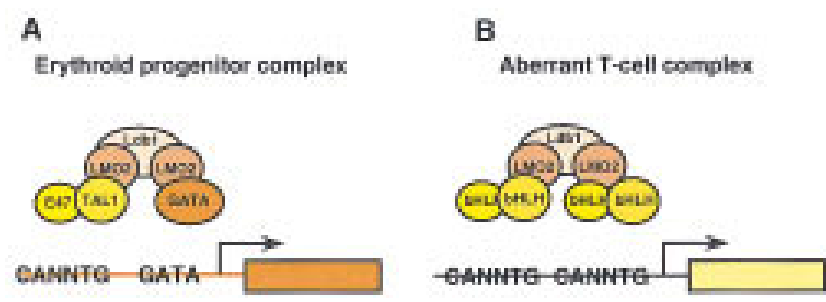

Figure 2. Lmo2 forms part of a complex which can bind a bi partite DN A site. (A) An erythroid Lmo2-containing complex. The ability of the $L \mathrm{mo} 2$ protein to interact with Tal 1 and with GATA1 appears to facilitate the formation of a complex in which two DNA contacting regions comprise an Tal1-E47 dimer, binding an E box (CANNTG), and a GATA1 molecule, binding a GATA site, as part of an erythroid complex. In model experiments (Wadman et al . 1997), the two parts of the bi partite DNA recognition sequence are separated by approximately one turn of the DNA helix. The function of this complex is presumably to bind to target genes and regulate their expression in erythropoiesis. If other complexes of this type, involving Lmo2, occur at other stages of hematopoiesis, these might bind and control distinct sets of target genes. (B) A T-cell Lmo2-containing aberrant complex. An anal ogous DN A-binding complex has been identified in $\mathrm{T}$ cells of Lmo2-expressing transgenic mice (Grutz et al. 1998). In this case, however, a novel complex is formed that recognizes a dual E-box motif (CANNTGCAN NTG), apparently involving bHLH heterodimers linked by Lmo2 and Ldb1 proteins. Like the distinct complex detected in erythroid cells, this Lmo2-containing complex may bind to dual E-box motifs near target genes and accordingly control their expression. An alternative function is proposed in Fig. 4.

1991; Warren et al. 1994; Robb et al. 1995; Shivdasani et al. 1995). Conversely, there are differences in some specific aspects of hematopoiesis related to the individual null mutations, suggesting that each of them can act in separate compl exes at different stages of hematopoi esis.

\section{Inhibition of differentiation by Lmo2 precedes T-cell leukemia}

Protein-protein interactions are crucial control points for normal cells, and alterations in these are important components in tumorigenesis after chromosomal translocations have taken place (for review, see Rabbitts 1994). The existence of an oligomeric complex in which Lmo2 protein is apparently a linking molecule in red bl ood cells suggests that the function of $\mathrm{Lmol}$ and $\mathrm{Lmo} 2$ proteins in T-ALL might be in aberrant complexes formed after the chromosomal translocation has enforced expression of the genes in $\mathrm{T}$ cells. Emulation of the enforced LMO1 or LMO2 human T-cell expression after chromosomal translocation has been achieved using transgenic mouse expression of Lmol (Fisch et al. 1992; M cGuire et al. 1992; A plan et al. 1997) and Lmo2 in the T-cell lineage (Fisch et al. 1992; Larson et al. 1994, 1995, 1996; Neale et al. 1995). This results in clonal Tcell leukemia arising in the transgenic mice with a long latency, indicating that the transgenes are necessary but not sufficient to cause tumors in these models, as is the case for many transgenic oncogene models (Adams and 
Cory 1991) and that mutations in other oncogenes or tumor suppressor genes occur before development of overt disease.

The long latency period before tumors arise in Lmo2 transgeni cs facilitated detailed studies of possible effects in the asymptomatic thymuses of transgenic mice (Larson et al. 1994, 1995, 1996; N eale et al. 1995). An outline of normal T-cell differentiation is shown in Figure 3, which illustrates the individual points in T-cell development. There was a marked accumulation of immature $\mathrm{CD}^{-}, \mathrm{CD} 8^{-}, \mathrm{CD} 25^{+}$, and CD $44^{+} \mathrm{T}$ cells (herein referred to as double negative or DN T cells) in transgenic thymuses compared to nontransgenic littermates, an effect that was exacerbated in mice transgenic for both $\mathrm{Lmo} 2$ and Tal 1 (Larson et al. 1996). Thus, the role of the transgene products is to cause an inhibition in T-cell differentiation, which appears reversible, presumably by antigenic stimulation occurring after birth, as different transgenic mice exhibit different levels of DN cell accumulation.

It is noteworthy that the DN T-cell population is RAG $\mathrm{V}(\mathrm{D})$ ] recombinase positive. Chromosomal transl ocation breakpoint sequencing (mentioned earlier) suggested that TCR rearrangement, mediated by recombinase, causes the formation of aberrant chromosomes in humans and, in turn, suggests that T-ALL precursors in humans acquire the LMO 2 chromosomal translocations within the DN T-cell population. If so, this would produce a cell with inhibited differentiation, analogous to those of transgenic mice (Fig. 3), providing the precursors

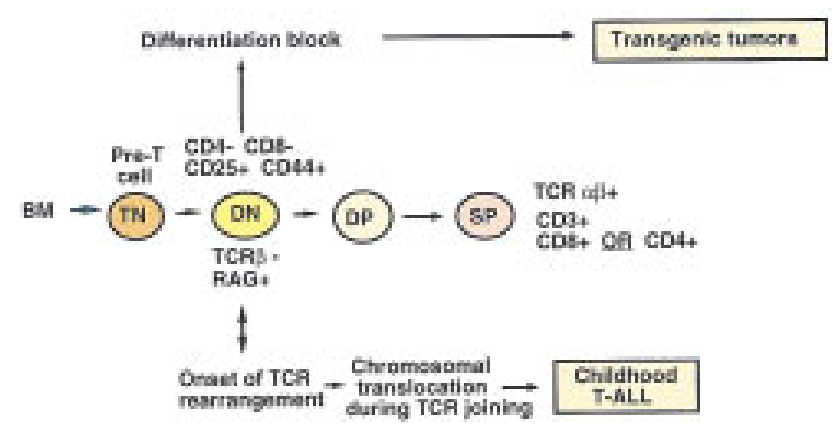

Figure 3. Inhibition of T-cell differentiation model for $\mathrm{Lmo2}$ function. Bone marrow produces pre-T cells (designated as TN because these cells do not yet express typical T-cell markers CD3, CD4, and CD8). These pre-T cells become DN cells (having a $\mathrm{CD} 4^{-}, \mathrm{CD} 8^{-}, \mathrm{CD} 25^{+}, \mathrm{CD} 44^{+}$marker phenotype), which do not yet express functional $T$-cell receptor (TCR) but begin to express the RAG recombinase proteins for performing $V(D)$ J recombination. Further differentiation of this immature DN Tcell subset results after TCR rearrangement, giving mature functional TCR-bearing T cells. The Lmo2 transgenic mice and double Lmo2-Tal 1 transgenics (Larson et al. 1996) accumulate the DN cells, apparently as a result of differentiation inhibition caused by the transgene. Because the LMO1 and LM O2-associated chromosomal translocations seem to result from RAG-mediated recombinase errors, it is proposed that this same target population of DN T cells is affected in humans with the chromosomal translocation. This would be the population from which the overt tumors arise. for overt tumor to arise, and can display other stages of T-cell differentiation.

\section{Protein interactions involving Lmo2 in T-cell leukemia}

The concept of inhibited differentiation mediated through creation of aberrant transcription complexes can be drawn from two observations. First, aberrant Lmo2 transgene expression upsets thymocyte differentiation. Second, the Lmo2 protein can be part of a DNA-binding complex in erythroid cells in which Lmo2 is a bridging molecule between the two DNA-binding arms of the complex, suggesting that enforced expression of LMO2, either by chromosomal translocation or by transgenesis, could mediate the formation of aberrant protein complexes. In a search for evidence of such Lmo2-containing complexes, T-cell lines derived from CD2-Lmo2 transgenic mice were used as a source of Lmo2 protein complexes (Grutz et al. 1998). This work resulted in the detection of a Lmo2 complex which, like its anal og in erythroid cells, binds to a bipartite recognition site; but in the T-cell line, the complex recognizes a dual E-box motif, in which the two E-box sequences are separated by about one DNA helical turn (Grutz et al. 1998) rather than the E box-GATA motif detected previously in erythroid cells (Wadman et al. 1997). Analysis of the components of this complex showed that E47-Tal $1 \mathrm{bHLH}$ heterodimeric elements were present as well as Lmo2 and the Ldb1 proteins (Fig. 2B). By analogy with arguments proposed for the normal erythroid E box-GATAbinding complex, a possible role for the E-box-E-boxbinding $T$-cell complex may be to regulate expression of specific sets of target genes which, based on the difference in DN A-binding site, would differ from those putative genes controlled by the Lmo2-multimeric complex in erythroid cells. Thus, enforced Lmo2 expression in $\mathrm{T}$ cells appears to facilitate the formation of an aberrant multimeric complex, which forms because Lmo2 has a binding affinity for these proteins. In an analogous way that multimeric complexes may vary and determi ne normal hematopoietic lineages, this aberrant complex may influence the T-cell lineage developmental program.

An al ternative explanation is worthy of consi deration. Although a complex of proteins may form because of affinities for the Lmo2 protein, it remains possible that the crucial interaction is with only one of the partners, thereby sequestering it from its normal function. Thus, a multicomponent complex may hide the true culprit responsible for a process of transcription dysregulation in tumorigenesis. This sequestration model is illustrated in Figure 4. Here, simple mass action effects, based on the relative concentrations of the interacting component, would influence the availability of individual proteins. The result of enforced LMO2 expression would be movement of the putative equilibrium to the left. In support of such a model is the evidence that the proportion of transgenic mice expressing Lmol or Lmo2 that develop tumors is rel ated to the transgene copy number (Fisch et al. 1992; M cGuire et al. 1992); the more transgenic copies, the more tumors occur, suggesting a titration of protein 


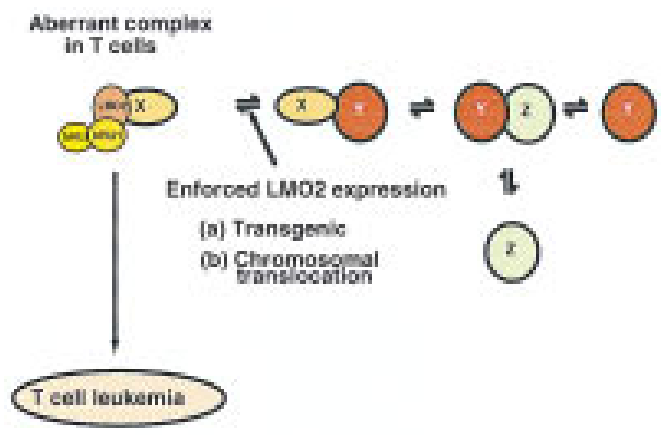

Figure 4. Sequestration model of $L m o 2$ function in $T-A L L$. The recognition of a novel bipartite DNA motif by an LMO2containing complex in T cells suggests that control of expression of target genes, carrying these binding sites, may be the function of the complex. An alternative sequestration model might be considered. In this model, the hypothetical proteins $X$ and $Y$ interact with each other and perform a necessary function in $T$ cells. This may be by forming an equilibrium of other interactions, such as with $\mathrm{Y}-\mathrm{Z}$ interactions or binding to target genes in the DNA. Enforced expression of LMO2 (using a transgene or after chromosomal translocation) al lows interaction of LM O2 with protein $X$, thereby sequestering this protein from its function in relation it interations with $Y$. The aberrant complex involving LM $\mathrm{O} 2$ and protein $\mathrm{X}$ may in real ity al so involve other proteins that would be found as part of the T-cell oligomeric complex. N otwithstanding their presence in such an oligomeric complex, the LMO2-X interaction is crucial to the molecular function and thus crucial to the effect of the chromosomal translocation in this model. Analogous models might apply to the role of LMO1.

components. It is also worth considering data about components of the Lmo2 T-cell complex. For instance, E2A null mice (loss of function) develop T-cell tumors (Bain et al. 1997; Yan et al. 1997) and display T-cell developmental defects, albeit different from those seen with Lmo2 transgenics, as the T cells appear to be more immature in the E47 null mice. No data exist about any possible involvement of Ldb1 in tumors and the chromosomal location of the gene in humans does not show any correlation with known chromosomal abnormalities (T.H. Rabbitts, A. Agulnick, Y. Ramsey, and N. Carter, unpubl.). However, the Drosophila Lmo gene homolog (Boehm et al. 1990a; Zhu et al. 1995), when mutated, causes wing defects that can be modified by the dosage of the Drosophila gene Chip (equival ent to Ldb1) (Shoresh et al. 1998), suggesting that Chip/Ldb can work by titrating binding partners.

\section{Conclusions}

The studies summarized in this paper on the LM O family of genes typify the characteristics that commonly occur in genes activated by chromosomal translocations, especially in acute forms of hematopoietic cancers and in mesenchymal origin tumors such as sarcomas (epithelial tumors have yet to characterized well enough in this respect; Rabbitts 1994). It is clear that chromosomal translocations are important in tumor etiology. These aberrant chromosomes are somatically formed and per- sist in the overt tumor. Despite their recurring nature, it is al so apparent that they are part of the manifold events needed for the appearance of overt disease and generally not sufficient to cause overt cancer.

There are two key steps by which the chromosomal translocations become fixed in the tumor cell. The first is to do with mechanism, and the second, with selection. Those chromosomal translocations that appear in lymphoid tumors are frequently associated with the rearranging antigen receptor genes and are interchromosomal mistakes of the $\mathrm{V}(\mathrm{D}) \mathrm{J}$ recombination process (either DN A sequence specific or not). The mechanism of those chromosomal translocations that result in gene fusion is not understood. The second step is paramount, as it is the selection of the cell which has acquired the aberrant chromosome because this confers some clonal advantage on the cell with it. The molecular basis of this clonal advantage is manifested through the function of the proteins made from the translocation-activated genes, namely their apparent ability to affect the transcriptional activity of the cell. Furthermore, the observations that developmental regulators are frequent targets of chromosomal translocations may also give us clues as to the clonal advantage. Thus, the ability of a protein product to influence cellular devel opment abnormally may reflect a proliferative advantage over its neighboring cells, because of the inappropriate differentiation circumstances of the pretumor cell. These considerations certainly indicate that chromosomal translocations are early events in the outgrowth of tumors.

Finally, the studies on proteins like LMO2, which are activated by chromosomal transl ocations, emphasize the importance of protein-protein interactions (in the LMO proteins mediated through LIM domains) in hematopoietic lineage determination and in tumorigenesis, and the potential that relatively small perturbations of protein binding equilibria can have for cell homeostasis. The notion is of negative regulation resul ting from chromosomal translocations. We might view many of the genes involved in acute leukemia chromosomal translocations as 'mild' effectors in the tumor pathway that influence the early course of cells, which can then move down the mutational pathway to the final outcome of overt cancer. Given that transcription regulators are key targets for chromosomal transl ocations in human cancer, a major objective now is to clone the genes that are affected by the altered transcription in cells with chromosomal translocations and determine their contribution to the malignant phenotype.

\section{Acknowledgments}

Our own work cited in this review was supported by the MRC and by grants from the Leukemia Research Fund (UK) and the $N$ ational Foundation for Cancer Research (USA).

\section{References}

Adams, J.M. and S. Cory. 1991. Transgenic models of tumor devel opment. Science 254: 1161-1167.

Agulnick, A.D., M. Taira, J.J. Breen, T. Tanaka, I.B. Dawid, and H. Westphal. 1996. Functional and physical interaction of 
Ldb1, a novel LIM domain binding factor, with the LIM homeodomain protein Lhx1/Xlim-1. Nature 384: 270-272.

A plan, P.D., C.A. Jones, D.S. Chervinsky, X.F. Zhao, M.K. Ellsworth, C. Wu, E.A. McGuire, and K.W. Gross. 1997. An scl gene product lacking the transactivation domain induces bony abnormalities and cooperates with LMO1 to generate T-cell malignancies in transgenic mice. EMBO J. 16: 24082419.

Bach, I., C. Carriere, H.P. Ostendorff, B. Andersen, and M.G. Rosenfeld. 1997. A family of LIM domain-associated cofactors confer transcriptional synergism between LIM and Otx homeodomain proteins. Genes \& Dev. 11: 1370-1380.

Bain, G., I. Engel, E.C.R. M aandag, H.P.J. Te Riele, J.R. Voland, L.L. Shart, J. Chun, B. Huey, D. Pinkel, and C. Murre. 1997. E2A deficiency leads to abnormalities in $\alpha \beta$ T-cell development and to rapid development of T-cell lymphomas. Mol. Cell. Biol. 17: 4782-4791.

Begley, C.G., P.D. A plan, M.P. Davey, K. N akahara, K. Tchorz, J. Kurtzberg, M.S. Hershfield, B.F. Haynes, D.I. Cohen, T.A. Waldmann, and I.R. Kirsch. 1989a. Chromosomal transl ocation in a human leukemic stem-cell line disrupts the T-cell antigen receptor $\delta$-chain diversity region and results in a previously unreported fusion transcript. Proc. Natl. Acad. Sci. 86: 2031-2035.

Begley, C.G., P.D. Aplan, S.M. Denning, B.F. Haynes, T.A. Waldmann, and I.R. Kirsch. 1989b. The gene SCL is expressed during early hematopoiesis and encodes a differentiation-related DN A-binding motif. Proc. Natl. Acad. Sci. 86: 10128-10132.

Bernard, O., P. Guglielmi, P. Jonveaux, D. Cherif, S. Gisselbrecht, M. M auchauffe, R. Berger, C.-J. Larson, and D. Mathieu-Mahul. 1989. Two distinct mechanisms for the SCL gene activation in the $t(1 ; 14)$ translocation of $\mathrm{T}$-cell leukemias. Genes Chromosomes Cancer 1: 194-210.

Boehm, T., R. Baer, I. Lavenir, A. Forster, J.J. Waters, E. N acheva, and T.H. Rabbitts. 1988. The mechanism of chromosomal translocation $\mathrm{t}(11 ; 14)$ involving the $\mathrm{T}$-cell receptor $\mathrm{C} \delta$ locus on human chromosome $14 q 11$ and a transcribed region of chromosome 11p15. EMBO J. 7: 385-394.

Boehm, T., L. Foroni, Y. Kaneko, M.P. Perutz, and T.H. Rabbitts. 1991. The rhombotin family of cysteine-rich LIM-domain oncogenes: Distinct members are involved in T-cell translocations to human chromosomes 11p15 and 11p13. Proc. Natl. Acad. Sci. 88: 4367-4371.

Boehm, T., L. Foroni, M. Kennedy, and T.H. Rabbitts. 1990a. The rhombotin gene bel ongs to a class of trancriptional regulators with a potential novel protein dimerisation motif. Oncogene 5: 1103-1105.

Boehm, T., J.M. Greenberg, L. Buluwela, I. Lavenir, A. Forster, and T.H. Rabbitts. 1990b. An unusual structure of a putative $T$ cell oncogene which allows production of similar proteins from distinct mRNAs. EMBO J. 9: 857-868.

Chen, Q., J.-T. Cheng, L.-H. T sai, N. Schneider, G. Buchanan, A. Carroll, W. Crist, B. Ozanne, M.J. Siciliano, and R. Baer. 1990a. The tal gene undergoes chromosome transl ocation in $T$ cell leukemia and potentially encodes a helix-loop-helix protein. EMBO J. 9: 415-424.

Chen, Q., C.Y.-C. Yang, J. Tsan, Y. Xia, A.H. Ragab, S.C. Pei per, A. Carroll, and R. Baer. 1990b. Coding sequences of the tal-1 gene are disrupted by the chromosome translocation in human T cell leukemia. J. Exp. Med. 172: 1403-1408.

Cleary, M.L. 1991. Oncogenic conversion of transcription factors by chromosomal translocations. Cell 66: 619-622.

Corral, J., I. Lavenir. H. Impey, A.J. Warren, A. Forster, T.A. Larson, S. Bell, A.N .J. M cKenzie, G. King, and T.H. Rabbitts. 1996. An MII-Af9 fusion gene made by homologous recom- bination causes acute leukemia in chimeric mice: A method to create fusion oncogenes. Cell 85: 853-861.

Croce., C.M., M. Shander, J. Martinis, L. Cicurel, G.G. D'Ancona, T.W. Dolby, and H. Koprowski. 1979. Chromosomal location of the genes for human immunoglobulin heavy chains. Proc. Natl. Acad. Sci. 76: 3416-3417.

Dube, I.D., S. Kamel-Reid, C.C. Yuan, M. Lu, X. Wu, G. Corpus, S.C. Raimondi, W.M. Crist, A.J. Carroll, J. Minowada, and J.B. Baker. 1991. A novel human homeobox gene lies at the chromosome 10 breakpoint in lymphoid neoplasias with chromosomal translocation t(10;14). Blood 78: 2996-3003.

Finger, L.R., R.C. Harvey, R.C.A. Moore, L.C. Showe, and C.M. Croce. 1986. A common mechanism of chromosomal translocation in T- and B-cell neoplasia. Science 234: 982-984.

Finger, L.R., J. Kagan, G. Christopher, J. Kurtzberg, M.S. Hershfield, P.C. N owell, and C.M. Croce. 1989. Involvement of the TCL 5 gene on human chromosome 1 in T-cell leukemia and melanoma. Proc. Natl. Acad. Sci. 86: 5039-5043.

Fisch, P., T. Boehm, I. Lavenir. T. Larson, J. Arno, A. Forster, and T.H. Rabbitts. 1992. T-cell acute lymphoblastic lymphoma induced in transgenic mice by the RBTN 1 and RBTN 2 LIM domain genes. Oncogene 7: 2389-2397.

Foroni, L., T. Boehm, L. White, A. Forster, P. Sherrington, X.B. Liao, C.I. Brannan, N.A. Jenkins, N.G. Copeland, and T.H. Rabbitts. 1992. The rhombotin gene family encode related LIM-domain proteins whose differing expression suggests multiple roles in mouse devel opment. J. Mol. Biol. 226: 747761.

Grutz, G., K. Bucher, I. Lavenir. R. Larson, T. Larson, and T.H. Rabbitts. 1998. The oncogenic LIM-protein Lmo2 forms part of a DN A-binding complex specifically in immature T cells. EMBO J. 17: 4594-4605.

Hatano, M., C.W.M. Roberts, M. Minden, W.M. Crist, and S.J. Korsmeyer. 1991. Deregulation of a homeobox gene, HOX11, by the t(10;14) in T cell leukemia. Science 253: 7982.

Hobart, M.J., T.H. Rabbitts. P.N. Goodfellow, E. Solomon, S. Chambers, N. Spurr, and S. Povey. 1981. Immunoglobulin heavy chain genes in humans are located on chromosome 14. Ann. Hum. Genet. 45: 331-335.

Hsu, H.-L., J.-T. Cheng, Q. Chen, and R. Baer. 1991. Enhancerbinding activity of the tal-1 oncoprotein in association with the E47/E12 helix-loop-helix proteins. Mol. Cell. Biol. 11: 3037-3042.

Hsu, H.-L., L. Huang, J.T. Tsan, W. Funk, W.E. Wright, J.-S. Hu, R.E. Kingston, and R. Baer. 1994. Preferred sequences for DNA recognition by the TAL1 helix-loop-helix proteins. Mol. Cell. Biol. 14: 1256-1265.

Jurata, L.W., D.A. Kenny, and G.N. Gill. 1996. Nuclear LIM interactor, a rhombotin and LIM homeodomain interacting protein, is expressed early in neuronal development. Proc. Natl. Acad. Sci. 93: 11693-11698.

Kennedy, M.A., R. Gonzal ez-Sarmiento, U.R. Kees, F. Lampert, N. Dear, T. Boehm, and T.H. Rabbitts. 1991. HOX11, a homeobox-containing $\mathrm{T}$-cell oncogene on human chromosome 10q24. Proc. Natl. Acad. Sci. 88: 8900-8904.

Larson, R., P. Fisch, T. Larson, I. Lavenir. T. Langford, G. King, and T.H. Rabbitts. 1994. T cell tumors with disparate phe notypes develop with long latency in mice transgenic for rbtn2. O ncogene 9: 3675-3681.

Larson, R.C., H. Osada, T.A. Larson, I. Lavenir, and T.H. Rabbitts. 1995. The oncogenic LIM protein Rbtn2 causes thymic devel opmental aberrations that precede malignancy in transgenic mice. Oncogene 11: 853-862.

Larson, R.C., I. Lavenir. T.A. Larson, R. Baer, A.J. Warren, I. Wadman, K. N ottage, and T.H. Rabbitts. 1996. Protein dimer- 
isation between Lmo2 (Rbtn2) and Tal 1 alters thymocyte development and potentiates $\mathrm{T}$ cell tumorigenesis in transgenic mice. EMBO J. 15: 1021-1027.

Look, A.T. 1997. Oncogenic transcription factors in the human acute leukemias. Science 278: 1059-1065.

Lu, M., Z. Gong, W. Shen, and A.D. Ho. 1991. The tcl-3 protooncogene altered by chromosomal translocation in T-cell leukemia codes for a homeobox protein. EMBO J. 10: 29052910.

Mal colm, S., P. Barton, C. M urphy, M .A. Ferguson-Smith, D.L. Bentley, and T.H. Rabbitts. 1982. Localisation of human immunogl obul in $\mathrm{\kappa}$ light chain variable region genes to the short arm of chromosome 2 by in situ hybridization. Proc. Natl. Acad. Sci. 79: 4957-4961.

Manolov, G. and Y. M anolov. 1972. Marker band in one chromosome 14 from Burkitt's lymphoma. Nature 237: 33-34.

McGuire, E.A., R.D. Hockett, K.M. Pollock, M.F. Bartholdi, S.J. O'Brien, and S.J. Korsmeyer. 1989. The t(11;14)(p15;q11) in a $T$-cell acute lymphobl astic leukemia cell line activates multiple transcripts, including Ttg-1, a gene encoding a potential zinc finger protein. Mol. Cel. Biol. 9: 2124-2132.

McGuire, E.A., C.E. Rintoul, G.M. Sclar, and S.J. Korsmeyer. 1992. Thymic overexpression of Ttg-1 in transgenic mice results in T-cell acute lymphoblastic leukemia/lymphoma. Mol. Cell. Biol. 12: 4186-4196.

Neale, G.A., J.E. Rehg, and R.M. Goorha. 1995. Ectopic expression of rhombotin-2 causes selective expansion of the thymus and T-cell tumors in transgenic mice. Blood 86: 30603071.

Nowell, P.C. and D.A. Hungerford. 1960. A minute chromosome in human granulocytic leukemia. Science 132: 14971500.

Osada, H., G. Grutz, H. Axelson, A. Forster, and T.H. Rabbitts. 1995. Association of erythroid transcription factors: Complexes involving the LIM protein RBTN 2 and the zinc-finger protein GATA 1. Proc. Natl. Acad. Sci. 92: 9585-9589.

Perez-Alvarado, G.C., C. Miles, J.W. Michelsen, H.A. Louis, D.R. Winge, M.C. Beckerle, and M .F. Summers. 1994. Structure of the carboxy-terminal LIM domain from the cysteine rich protein CRP. Nature Struct. Biol. 1: 388-398.

Pevny, L., M.C. Simon, E. Robertson, W.H. Klein, S.-F. Tsai, V. D'A gati, S.H. Orkin, and F. Costantini. 1991. Erythroid differentiation in chimaeric mice blocked by a targeted mutation in the gene for transcription factor GATA-1. Nature 349: 257-260.

Porcher, C., W. Swat, K. Rockwell, Y. Fujiwara, F.W. Alt, and S.H. Orkin. 1996. The T cell leukemia oncoprotein SCl/tal-1 is essential for development of all hematopoietic lineages. Cell 86: 47-57.

Rabbitts. T.H. 1991. Translocations, master genes, and differences between the origins of acute and chronic leukemias. Cell 67: 641-644.

- - . 1994. Chromosomal translocations in human cancer. Nature 372: 143-149.

Robb, L., J.E.J. Rasko, M.L. Bath, A. Strasser, and C.G. Begley. 1995. scl, a gene frequently activated in human $\mathrm{T}$ cell leukemia, does not induce lymphomas in transgenic mice. Oncogene 10: 205-209.

Robb, L., N.J. Elwood, A.G. Elefanty, F. Kontgen, R. Li, L.D. Barnet, and C.G. Begley. 1996. The scl gene product is required for the generation of all hematopoietic lineages in the adult mouse. EMBO J. 15: 4123-4129.

Rowley, J.D. 1973. A new consistent chromosomal abnormality in chronic myelogeneous leukemia identified by quinaurine fluorescence and giemsa staining. Nature 243: 290-293.

Royer-Pokora, B., U. Loos, and W.-D. Ludwig. 1991. TTG-2, a new gene encoding a cysteine-rich protein with the LIM motif, is overexpressed in acute T-cell leukemia with the $\mathrm{t}(11 ; 14)(\mathrm{p} 13 ; \mathrm{q11})$. Oncogene 6: 1887-1893.

Sanchez-Garcia, I. and T.H. Rabbitts. 1994. Transcriptional activation by TAL1 and FUS-CHOP proteins expressed in acute malignacies as a result of chromosomal abnormalities. Proc. Natl. Acad. Sci. 91: 7869-7873.

Sanchez-Garcia, I., Y. Kaneko, R. Gonzalez-Sarmiento, K. Campbell, L. White, T. Boehm, and T.H. Rabbitts. 1991. A study of chromosome 11p13 translocations involving TCR $\beta$ and TCR $\delta$ in human T cell leukemia. Oncogene 6: 577-582.

Schmeichel, K.L. and M.C. Beckerle. 1994. The LIM domain is a modular protein-binding interface. Cell 79: 211-219.

Shivdasani, R.A., E. Mayer, and S.H. Orkin. 1995. Absence of blood formation in mice lacking the $\mathrm{T}$-cell leukemia oncoprotein tal-1/SCL. Nature 373: 432-434.

Shoresh, M., S. Orgad, O. Shmueli, R. Werczberger, D. Gelbaum, S. Abiri, and D. Segal. 1998. Overexpression Beadex mutations and loss-of-function heldup-a mutations in Drosophila affect the $3^{\prime}$ regulatory and coding components, respectively of the DImo gene. Genetics (in press).

Val ge-Archer, V.E., H. Osada, A.J. Warren, A. Forster, J. Li, R. Baer, and T.H. Rabbitts. 1994. The LIM protein RBTN 2 and the bHLH protein TALI are present in a complex in erythroid cells. Proc. Natl. Acad. Sci. 91: 8617-8621.

Val ge-Archer, V., A. Foster, and T.H. Rabbitts. 1988. The LMO1 and LDB1 proteins interact in human T cell acute leukaemia with the chromosomal translocation $\mathrm{t}(11 ; 14)(\mathrm{p} 15 ; \mathrm{q} 11)$. Oncogene (in press).

Wadman, I., J. Li, R.O. Bash, A. Forster, H. Osada, T.H. Rabbitts. and R. Baer. 1994a. Specific in vivo association between the bHLH and LIM proteins implicated in human T cell leukemia. EMBO J. 13: 4831-4839.

Wadman, I.A., H.-L. Hsu, M.H. Cobb, and R. Baer. 1994b. The MAP kinase phosphorylation site of TAL1 occurs within a transcriptional activation domain. Oncogene 9: 3713-3716.

Wadman, I.A., H. Osada, G.G. Grutz, A.D. Agulnick, H. Westphal, A. Forster, and T.H. Rabbitts. 1997. The LIM-only protein Lmo2 is a bridging molecule assembling an erythroid, DNA-binding complex which includes the TAL1, E47, GATA-1 and Ldb1/N LI proteins. EMBO J. 16: 3145-3157.

Warren, A.J., W.H. Colledge, M.B.L. Carlton, M.J. Evans, A.J.H. Smith, and T.H. Rabbitts. 1994. The oncogenic cysteine-rich LIM domain protein rbtn2 is essential for erythroid development. Cell 78: 45-58.

Yamada, Y., A.W. Warren, C. Dobson, A. Forster, R. Pannell, and T.H. Rabbitts. 1998. The T cell leukemia LIM protein Lmo2 is necessary for adult mouse hematopoiesis. Proc. Natl. Acad. Sci. 95: 3890-3895.

Yan, W., A.Z. Young, V.C. Soares, R. Kelley, R. Benezra, and Y. Zhuang. 1997. High incidence of T-cell tumors in E2A-null mice and E2A/Idl double-knockout mice. Mol. Cell. Biol. 17: 7317-7327.

Zech, L., U. Hagland, K. Nilsson, and G. Klein. 1976. Characteristic chromosomal abnormalities in biopsies and lymphoid cell lines from patients with Burkitt's and nonBurkitt's lymphomas. Int. J. Cancer 17: 47-56.

Zhu, T.-H., J. Bodem, E. Keppel, R. Paro, and B. Royer-Pokora. 1995. A single ancestral gene of the human LIM domain oncogene family LMO in Drosophila: Characterisation of the Drosophila DImo gene. Oncogene 11: 1283-1290. 


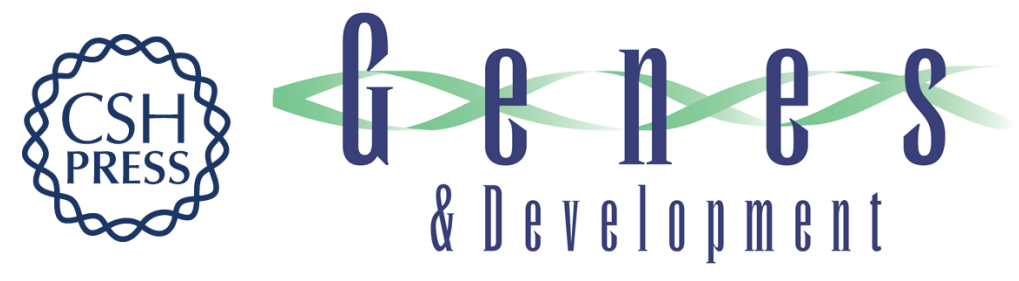

\section{LMO T-cell translocation oncogenes typify genes activated by chromosomal translocations that alter transcription and developmental processes}

Terence H. Rabbitts

Genes Dev. 1998, 12:

Access the most recent version at doi:10.1101/gad.12.17.2651

References This article cites 62 articles, 29 of which can be accessed free at:

http://genesdev.cshlp.org/content/12/17/2651.full.html\#ref-list-1

License

Email Alerting Receive free email alerts when new articles cite this article - sign up in the box at the top

Service right corner of the article or click here.

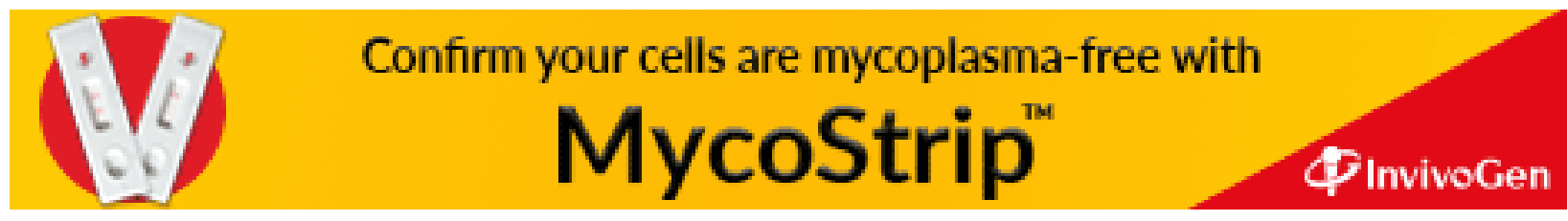

